\title{
Analysis on Practical Application of "PK" Teaching Model in the Teaching of Calisthenics Course
}

\author{
Jianling Li \\ Department of Physical Education, Xi'an International University, Xi'an, 710077, China
}

Keywords: Calisthenics; teaching; "PK" teaching model; practical application; analysis

\begin{abstract}
With the continuous development and perfection of science and technology, the teaching means are improved. The calisthenics course in colleges gradually develops from traditional teaching model and diversified direction and "PK" teaching model has appeared and used in the classroom. Through contrast experiment, the calisthenics course provision in colleges is checked, the influence of "PK" operation on the teaching of calisthenics is discussed, the problems in "PK" teaching model and the principles followed in the process of "PK" teaching model operation are analyzed in this paper.
\end{abstract}

\section{Introduction}

At present, the education and teaching rules and regulations and other conditions of physical education major determine that the calisthenics course is in the traditional teaching stage, without no obvious teaching effects. To effectively improve the teaching quality of calisthenics in colleges, it is required to make bold innovations and try various teaching models. The use of "PK" teaching model can improve students' calisthenic skills and promote the harmonious development of students' physical and psychological health to a certain degree. Next, "PK" teaching model is deeply studied and discussed in order to be better used in the classroom.

\section{Setting of the operating procedure of "PK" teaching model}

Operating procedure of "PK" teaching model refers to one that changes the teaching model of physical education major under the background of modern higher education reform and that the teacher conducts teaching in a "PK" form under the guidance of "PK" teaching thought and model with the existing calisthenics teaching experience and combined with the features of calisthenics.

"PK" teaching model has 7 stages, in which there is a clear teaching goal respectively as follows:

1. Phase 1 - Teaching of basic knowledge by teacher

The teacher teaches the students the basic calisthenics knowledge and skills first and then teaches them knowledge and skills about "PK".

2. Phase 2 - "PK" grouping of students by teacher

The teacher divides the students into groups reasonably according to their height and ability as well as teaching needs. With 4-6 students, the students of each group should not be changed randomly, which is conducive to unite the centripetal forces of students in the group.

3. Phase 3 - Assignment of group's learning task

The teacher assigns the learning task of each group according to the calisthenics teaching progress, provides different learning contents and methods to students and sets the calisthenics movement as compulsory technical movements and self-made movements.

4. Phase 4 - Rehearsal and exercise of movements by each group

Each group communicates with each other fully, exercises diligently and masters the movements as stipulated by the teacher, rehearses "PK" routines by putting heads together, carries out cooperation and makes bold innovation.

5. Phase 5 - conduction of "PK" activities between groups

The teacher organizes the groups for "PK" communication and each group shows their rehearsed or mastered movements. 
6. Phase 6 - teacher's evaluation

The teacher chooses a winning group according to the "PK" state and innovation of each group, and then puts forward opinions and suggestions on the problems of other groups and encourages students to do continuing efforts.

7. Phase 7 - Summarization of teaching unit

Teaching comes to an end. The teacher summarizes the whole learning process and assign the content of next course to make students prepared.

\section{Practical application in teaching}

The students of two classes of physical education major are of contrast experiment, in which one class is divided into different groups and the other class is taken as control class. Under contrastive teaching, the experimental class adopts "PK" teaching model and the control class adopts traditional teaching model to lead students to exercise with explanation of teacher. According to the physical quality involved by calisthenics, some items are used as the evaluation indexes of students' physical quality, such as height, 50m sprint, sit-and-reach, sit-up and stairs experiment. The measuring tools are comprehensive and proper, such as second chronograph and tape and the measurement is subject to the principle of fair and justice.

The experiment lasts for one semester and there are only two 40-minute courses in a week. The conditions of two classes are the same except the teaching model and procedure. To eliminate the personal preference of the teacher on certain or some students, the double-blind method is adopted for scoring. In the final examination, several calisthenics teachers score the students and the scoring standard is to conduct fair evaluation according to the rules of competition of calisthenics as well as movement representation, basic formation, harmony and innovative rehearsal.

This experiment also applies to check students' teamwork spirit. A questionnaire can be developed, in which the options of different depth can be listed according to students' group cohesion and then the influence of group cohesion on student's calisthenics learning can be analyzed according to the difference of experiment class and control class before and after experiment.

\section{Analysis results}

(I) Compare the physical quality of students in experimental class and control class before experiment

To ensure the fairness and reliability of experimental results, the physical quality of students in the experimental class and control class is measured before experiment and the experimental indicator measurement shows that the students of the two classes have no obvious difference at all aspects. This indicates that the students of two classes have no advantage difference in the physical quality. In addition, no students have contacted calisthenics since the childhood, thus increasing the experimental reliability.

(II) Analyze the influence of "PK" teaching model on students' calisthenics performance

After one-semester teaching experiment, the teacher scores the students according to the assessment content and the results show that there is obvious difference. The student performance in the experimental class is obviously better than the control class, especially in the basic formation and movement standardability. Therefore, "PK" teaching model makes the calisthenics teaching more interesting and new and "PK" method enhances students' group cohesion. In addition, every student has stricter requirements on themselves and exercise hardly to get better performance.

The importance of innovation in the teaching of calisthenics is embodied fully in the teaching. Students actively express their opinions in rehearsal of movement routine, learn teamwork and make common progress. This "PK" teaching model and its assessment procedure do not adopt traditional individual type test, but team test, in which timid students can overcome their psychological barriers and show their excellent aspect. Compared with the teaching effects of traditional model of control class, the learning effects of experimental class are better. 
(III) Analyze the influence of "PK" teaching model on students' teamwork spirit

In phase 2 of the operating procedure of "PK" teaching model, students are divided into groups for "PK" and then assessed by means of group competition, thus promoting the cooperation between members of each group because students can show the best calisthenics with their tactic cooperation and get the ideal performance under their common efforts. This method effectively promotes the common progress of students and also continuously enhance their group cohesion.

The physical quality of students in the experimental class and control class is tested before experiment and the results show that there is no obvious difference; however, the group cohesion is found of significant difference at the end of semester. This indicates that the students in the experimental class have obvious improvement after "PK" teaching procedure, so this method promotes the cultivation of students' teamwork spirit to a certain degree.

\section{Problems in "PK" teaching model}

"PK" teaching model has made significant achievements at many aspects, but there is still certain problem in it:

(I) Difficult implementation at the beginning

"PK" teaching model differs greatly from the traditional teaching model and has many difference in procedure. "PK" teaching often has more operation procedure and complicated steps, including group learning and group competition. As the teacher and students have been customized to the traditional education method, so they don't adapt to this new teaching model and some of them even have an emotion of resistance and fear. Therefore, this teaching model is implemented hardly at the beginning.

(II) Higher requirements on teacher and students compared with the traditional model

"PK" teaching model requires the calisthenics teacher to have strong organization and planning ability to control the class, solid basic skills of calisthenics education and certain psychological knowledge and social knowledge base as well as various comprehensive abilities for communication with students. This model requires the students to have strong teamwork and self-learning ability and requires the leader of each group have certain organization and anti-pressure ability to maximize the learning efficiency.

(III) Difficult mastering of teaching time

In the operating procedure of "PK" teaching model, most of the time are for self discussion of learning of students. The self discussion requires the students to have an embryo of basic movement and innovative routine rehearsal. However, due to the different learning efficiency of each group, some groups are prepared for "PK" and some groups are not well prepared. In addition, there are some other circumstances that will lead to unreasonable time control.

(IV) Great difficulty in effective regulation

"PK" teaching model has complicated operating procedure, diversified contents and many links and students are of self learning in most cases. Due to the strong laziness of some students, they may have such problems as discussion of other things, low learning efficiency and participation. However, the teacher, with limited energy, cannot consider all students, thus leading to the influence on the teaching progress and over-lively atmosphere. In addition, some young calisthenics teacher, with insufficient ability and experiences, cannot control the class, thus affecting the teaching progress and efficiency.

\section{Principles followed by "PK" teaching model during operation}

(I) Reasonable teaching goal

The premise of the application of "PK" teaching model in the teaching of calisthenics is the reasonable teaching goal. The calisthenics teacher should define the teaching goal before teaching and lead the students to conduct learning and exercise for this teaching goal in order to achieve such goal. The reasonable teaching goal is that the teacher determines the teaching content with good predicted effects that can be completed by students in accordance with the requirements of teaching 
outline and combined with students' actual situation.

(II) Reasonable "PK" grouping

As students are assessed by means of group competition in the "PK" teaching model, so the grouping must be reasonable. The teacher should divide students into groups with equivalent ability, choose the student that are actively, initiative and leading as the group leader, assign the task and define the learning content of each group.

(III) Comprehensive evaluation

In evaluating students' "PK" performance at the end of semester, the teacher should follow the principle of comprehensive evaluation to evaluate the performance of such student in terms of learning attitude, progress and teamwork spirit from the start of calisthenics course to the end of "PK" activity. In addition, the teacher should also follow up and observe the student properly and give correct comment and guidance to the deficiencies of student.

\section{Conclusion}

The practical analysis of "PK" teaching shows this teaching model for calisthenics is conducive to cultivate students' group cohesion and has certain scientificity and effectiveness in students' group consciousness. In addition, it provides a good way for students to quickly master the basic movement and skill of calisthenics, improves students' innovative consciousness to a certain degree and also effectively improve the teaching quality.

\section{References:}

[1] Li Aiqin. Practice of Graded Teaching in the Teaching of Engineering Thermodynamics[A]. Refrigeration Air Conditioner Discipline Development and Teaching Research_— Proceedings of the 6th National University Refrigeration Air Conditioner Discipline Development and Teaching Workshop[C],2010.

[2] Zhang Weimin. Insist on Subject Experiment, Improve School Grade-Summarization of "Teacher Team Construction and Backbone Teacher Cultivation" Subject[A]. Results Set of National Teacher's Scientific Research Foundation During "Eleventh Five-Year Plan" (Chinese Universities Volume) (III)[C],2009.

[3] Han Dong, Wu Yaoyu. Provide Human Resource Guarantee for Comprehensive Construction of Well-Off Sports__Research on Structural Optimization and Reasonable Layout of Physical Education Major of Colleges in Shandong Province[A]. Abstracts of the 7th National Olympic Scientific Congress (I)[C],2004.

[4] Ge Cuibai, Huang Jixiong, Shi Jinling, Ge Jianzhu, Chen Jianbin. Discussion on Course Teaching Reform of Ideological and Moral Cultivation and Basic Law Education in Physical Education Colleges__ Taking Nanjing Sport Institute as an example[J]. Journal of Nanjing Sport Institute (Natural Science Edition), 2010(04).

[5] Liu Tao, Zhang Jiujian, Ma Shengli, Wang Xiangying, Wang Meichun. Statistical Analysis and Research on Students' Physical Quality Examination Performance of Physical Education Major in Colleges[A]. Abstracts of the 7th National Olympic Scientific Congress (II)[C],2004.

[6] Zhou Zhixiong, Ji Gang, Zhang Fan, Wu Min, Sheng Chunyuan, Wang Zhihui, Gu Fang, Yang Junqing. Empirical Research on Effectiveness of Vascular Function Evaluation Index of College Students in National Student's Physical Health Standard[J]. Journal of Capital Institute of Physical Education,2009(01).

[7] Xu Lianyu. Change from Traditional Classroom to Network-based Classroom Teaching__Final Report of "Collaborative Inquiry Teaching" Teaching Model of Information Technology Discipline[A]. Proceedings of CAET 2004 Annual Meeting[C],2004. 
[8] Chen Zhiqiang, Jin Xiaofeng, Zhao Jun, Huang Xiaoling. Comparative Research on Influences of Height and Weight on Physical Function and Quality of Male College Students[A]. Abstracts of CAST 2005 Academic Annual Conference Sports Science Venue[C],2005.

[9] Sun Xiaoping, Research Group of Fangxian No.1 Middle School, Shiyan City, Hubei Province. Way of Improving Teaching Practice of Sprint Performance and Targeted Training of Physical Education Candidates at Our School[A]. Results Set of National Teacher's Scientific Research Foundation During "Eleventh Five-Year Plan" (Chinese Universities Volume) (V)[C],2009.

[10] Wang Dingguo, Lin Ruohong. Building of "Student-oriented" Higher Vocational Education Curriculum System[A]. Proceedings of "Vocational Education and Harmonious Society and Western Taiwan Straits Economic Zone Construction" Seminar \& the 13th Vocational Education Theory Seminar[C],2005. 